\title{
Immunological effect induced by mesenchymal stem cells in a rat liver transplantation model
}

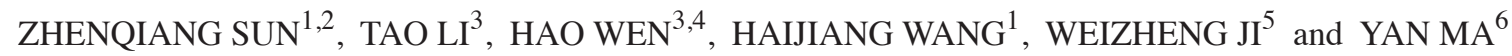 \\ ${ }^{1}$ Department of Gastrointestinal Surgery, Affiliated Tumor Hospital, Xinjiang Medical University, \\ Ürümqi, Xinjiang 830011; ${ }^{2}$ Research Laboratory of Disease Genomics, Cancer Research Institute, \\ Central South University, Changsha, Hunan $410078 ;{ }^{3}$ Department of Digestive and Vascular Surgery Center; \\ ${ }^{4}$ Xinjiang Organ Transplant Research Institute; ${ }^{5}$ Oncology Center; ${ }^{6}$ Stem Cell Laboratory of Medical Research Center, \\ First Affiliated Hospital, Xinjiang Medical University, Ürümqi, Xinjiang 830054, P.R. China
}

Received March 27, 2014; Accepted November 12, 2014

DOI: $10.3892 / \mathrm{etm} .2015 .2551$

\begin{abstract}
The aim of the present study was to investigate the immunological effect induced by bone marrow mesenchymal stem cells (MSCs) in rats that had undergone an orthotopic liver transplantation (OLT). MSCs were isolated and cultured from the bone marrow tissue of Lewis rats. In total, 42 rat OLT models were established and equally distributed into three groups. Group A received an OLT only, group B were also intramuscularly injected with tacrolimus (FK506), while group C were not only administered FK506, but also received MSCs. On day 7 post-surgery, the blood levels of alanine aminotransferase (ALT), aspartate aminotransferase (AST) and total bilirubin (TBIL) were measured. In addition, pathological changes were observed in the liver, levels of immune cytokines, including transforming growth factor (TGF)- $\beta_{1}$, interleukin (IL)-10 and IL-12, were determined using immunohistochemistry, MSC homing was assessed and the survival times of the patients were recorded. Liver function, as assessed by the levels of ALT, AST and TBIL, was shown to improve in group $\mathrm{C}$ when compared with groups $\mathrm{B}$ and $\mathrm{A}$ (both $\mathrm{P}<0.01$ ). In addition, survival analysis revealed that the survival times in groups B (median, 44 days) and C (median, 63 days) were significantly longer compared with group A (median, 11 days; both $\mathrm{P}<0.01)$. The survival rate of group $\mathrm{C}$ was also higher compared with group $\mathrm{B}(\mathrm{P}<0.01)$. Pathological examination demonstrated strong acute rejection in group $\mathrm{A}$, a mild acute rejection in group $B$ and the mildest reaction in group $C$. In addition, immunohistochemistry revealed that TGF- $\beta_{1}$ and IL-10 expression was stronger in groups $C$ and $B$,
\end{abstract}

Correspondence to: Professor Hao Wen, Department of Digestive and Vascular Surgery Center, First Affiliated Hospital, Xinjiang Medical University, 1 Liyu Shan Road, Ürümqi, Xinjiang 830054, P.R. China

E-mail: doctor_qq@163.com

Key words: mesenchymal stem cells, orthotopic liver transplantation, immune effect, animal model with group $\mathrm{C}$ exhibiting more significant expression than group B. By contrast, expression levels of IL-12 in groups A, $\mathrm{B}$ and $\mathrm{C}$ were positive, weak-positive and negative, respectively. Therefore, postoperative immunosuppression induced by MSCs is important for the alleviation of immune rejection from recipient-to-graft, and may induce immune tolerance in rat OLT models.

\section{Introduction}

From the first orthotopic liver transplantation (OLT) by Thomas Starzl (1), liver transplantation has become an effective therapeutic option for the treatment of end-stage liver disease. However, postoperative immune rejection is the main cause for early stage liver dysfunction following liver transplantation. Immune rejection is also associated with various other complications, such as pulmonary disease. In a previous study by Bozbas et al (2), pulmonary complications were detected in $42.1 \%$ of liver recipients; pneumonia, in $21.1 \%$; and pleural effusion on early postoperative chest radiographs, in $32.5 \%$. In clinical practice, an immune rejection response can be partly controlled by a number of novel immunosuppressants, which are required by almost all patients for prolonging the survival time. However, these drugs are associated with a number of issues, including high costs and numerous side effects. In addition, chronic immune rejection is inevitable (3-5). A number of in vitro studies (6-9) have reported that mesenchymal stem cells (MSCs) produce an immunosuppressive effect. MSCs have also been demonstrated, by Wood et al (10), to have important roles in the induction of immune tolerance following organ transplantation in vivo. MSCs suppress allogeneic $\mathrm{T}$ cell responses by secreting soluble factors, such as prostaglandin E2, interleukin (IL)-10 and IL-6 (11). Kordelas et al suggested that MSC-derived exosomes, which are released by exocytosis from the plasma membrane, may benefit therapy-refractory patients with graft versus-host disease (12). Therefore, the aim of the present study was to clarify the immunological effect induced by bone marrow MSCs in rats that had undergone an OLT, in order to establish a theoretical base for improving the survival times of patients undergoing a liver transplantation. 


\section{Materials and methods}

Animals and reagents. In total, 42 female Lewis rats and 42 female Brown Norway rats were used as donors and recipients. Two male Lewis rats were randomly chosen for the extraction of MSCs. All the rats (weight, 180-220 g; age, three months) were provided by the Experimental Animal Center of Xinjiang Medical University (Ürümqi, China), and were housed with free access to water. Low glucose Dubecco's modified Eagle's medium (LG-DMEM) was purchased from Gibco Life Technologies (Carlsbad, CA, USA) and good grade fetal bovine serum (FBS) was obtained from Hangzhou Sijiqing Biological Engineering Materials Co., Ltd. (Hangzhou, China). Trypsin (1:250) was purchased from Blue quarter of Shanghai Science and Technology Development Co. (Shanghai, China). Both L-glutamine and poly-L-lysine were obtained from Sigma-Aldrich (St. Louis, MO, USA). An inverted phase contrast microscope (CKX41-A32PH) was obtained from Olympus Corporation (Tokyo, Japan). Rabbit anti-rat antibodies targeted against interleukin (IL)-10 (cat. no. bs-6761R), IL-12 (cat. no. bs-10641R) and transforming growth factor (TGF)- $\beta_{1}$ (cat. no. bs-0086R) were purchased from Beijing Boao Sen Biotechnology Co., Ltd. (Beijing, China). A rabbit two-step kit (PV6001) was obtained from Beijing Zhongshan Golden Bridge Biotechnology Co., Ltd. (Beijing, China) and a SRY in situ hybridization detection kit was purchased from Wuhan Bo Shide Biological Engineering Co., Ltd. (MK1034; Wuhan, China).

Isolation, culture and identification of MSCs. Following abdominal administration of $4 \%$ chloral hydrate anesthesia ( $1 \mathrm{ml} / 100 \mathrm{~g}$; Qingdao Yulong HAIZAO Co., Ltd., Qingdao, China), male Lewis rats were sacrificed and the femur was obtained. The bone samples were immersed in $0.2 \%$ penicillin-streptomycin solution (XB-100X; Guangzhou Xiang Bo Biological Technology Co., Ltd., Guangzhou, China) and then flushed by PBA-A. The femoral epiphysis was harvested and the cavitas medullaris were repeatedly washed with LG-DMEM solution. Next, $\sim 50 \mu 1$ mixed bone marrow cell suspension was collected, dyed with trypan blue and counted on a cell count board under a LEICA ortho microscope (Leica Microsystems $\mathrm{GmbH}$, Wetzlar, Germany). The cell density was adjusted to $6-8 \times 10^{6} / \mathrm{ml}$, after which $10 \%$ FBS was added and the cells were inoculated in the culture flask for culture. After $48 \mathrm{~h}$, the liquid was changed for the first time and the non-adherent cells were removed. When the cultured MSCs reached $~ 90 \%$ cell fusion degree, they were subcultured into new culture bottles at a cell density of $2-5 \times 10^{5} / \mathrm{ml} .0 .125 \%$ trypsinization was used for serial subcultivation. A cell suspension of the third generational passage was collected with a density of $2 \times 10^{4} / \mathrm{ml}$ and centrifuged at $250 \mathrm{xg}$ for $5 \mathrm{~min}$ at $4^{\circ} \mathrm{C}$. Subsequently, the cells were passed through a $200 \mu \mathrm{m}$ filter and the density was adjusted to $2 \times 10^{6} / \mathrm{ml}$. Finally, the cells were stored in a refrigerator at $4^{\circ} \mathrm{C}(13,14)$.

Animal model establishment. Rat OLT models were established according to the modified classic 'two-cuff technique' (15). A successful model was defined by the recipient living for $>48 \mathrm{~h}$. In general, the rats were able to drink water containing $10 \%$ glucose immediately following consciousness, with free access to food one day after the OLT. All the rats were divided equally at random into three groups. Group A rats underwent the OLT only, group B were intramuscularly injected with tacrolimus (FK506; $2 \mathrm{mg} / \mathrm{kg} / \mathrm{day}$ ) for one month following the OLT, while group C rats were administered not only FK506, but also a suspension of MSCs $\left(1 \times 10^{6} / 200 \mathrm{~g}\right)$ infused through the portal vein immediately following bile duct anastomosis. Ethical approval was obtained from the Medical Ethics Committee of the Affiliated Tumor Hospital of Xinjiang Medical University (no. W-201309).

Specimen collection and measurement. On day 7, six rats that had undergone an OLT were randomly sacrificed in each group for hepatic function and pathological analysis. Alanine aminotransferase (ALT), aspartate aminotransferase (AST) and total bilirubin (TBIL) levels were analyzed. Pathological examination was performed on the grafts using hematoxylin and eosin staining, while the levels of various cytokines, including TGF- $\beta_{1}$, IL-10 and IL-12, were measured by immunohistochemistry using a rabbit two-step kit according to the manufacturer's instructions. SRY in situ hybridization was applied to locate the MSCs containing a Y chromosome (from the male donor). The remaining eight rats from each group that had undergone an OLT were observed for survival rates. The procedures were conducted according to the methods of Wei et al (16).

Statistical analysis. SPSS 15.0 (SPSS, Inc., Chicago, IL, USA) software was used for statistical analysis. Analysis of variance was used to analyze the levels of AST, ALT and TBIL in the three groups. Least significance difference analysis was performed to assess the differences among the groups. Statistical analysis of the expression of TGF- $\beta_{1}$, IL-10 and IL-12 in the three groups was carried out using a Kruskal-Wallis test. Comparisons between the levels of these three cytokines in two groups were conducted using a Mann-Whitney U test (adjusted $\alpha^{\prime}=0.05 / 3$ ) In addition, Kaplan-Meier survival curves and the log-rank test were performed to analyze the survival rates. Experimental data are expressed as the mean \pm standard deviation. $\mathrm{P}<0.05$ was considered to indicate a statistically significant difference.

\section{Results}

Morphological changes to the MSCs. At $72 \mathrm{~h}$ after the primary culture of MSCs, there were a number of oval-shaped adherent cells and a small number of cells undergoing stretching and deformation, presenting as a polygon or fusiform-shaped (Fig. 1-A1). These cells proliferated rapidly and formed clones after three to five days. A small number of cells were confluent (cells in the first generational passage; Fig. 1-A2), and up to $90 \%$ confluency was achieved after seven or eight days. The third generational passage cells were almost all adhered to the wall and evenly spread, with a typical uniform long spindle morphology. These cells also proliferated rapidly, and $>90 \%$ confluency was achieved after four or five days, presenting as whirlpool and pectiniform shapes (Fig. 1-A3).

General situation following the OLT. Between days 2 and 3 after the OLT, the recipients in group A appeared very 
Table I. Comparison of hepatic function among the three groups on day 7 following OLT.

\begin{tabular}{lcccc}
\hline Groups & Cases (n) & ALT (U/l) & AST (U/l) & TBIL $(\mu$ mol/l) \\
\hline Group A & 6 & $733.00 \pm 69.45$ & $645.00 \pm 94.16$ & $98.50 \pm 5.58$ \\
Group B & 6 & $274.50 \pm 50.47^{\mathrm{a}}$ & $344.50 \pm 60.03^{\mathrm{a}}$ & $38.17 \pm 2.86^{\mathrm{a}}$ \\
Group C & 6 & $114.67 \pm 21.96^{\mathrm{a}, \mathrm{b}}$ & $151.33 \pm 16.68^{\mathrm{a}, \mathrm{b}}$ & $17.00 \pm 1.41^{\mathrm{a}, \mathrm{b}}$ \\
\hline
\end{tabular}

${ }^{\mathrm{a}} \mathrm{P}<0.01$, vs. group $\mathrm{A} ;{ }^{\mathrm{b}} \mathrm{P}<0.01$, vs. group B. ALT, alanine aminotransferase; AST, aspartate aminotransferase; TBIL, total bilirubin; OLT, orthotopic liver transplantation.

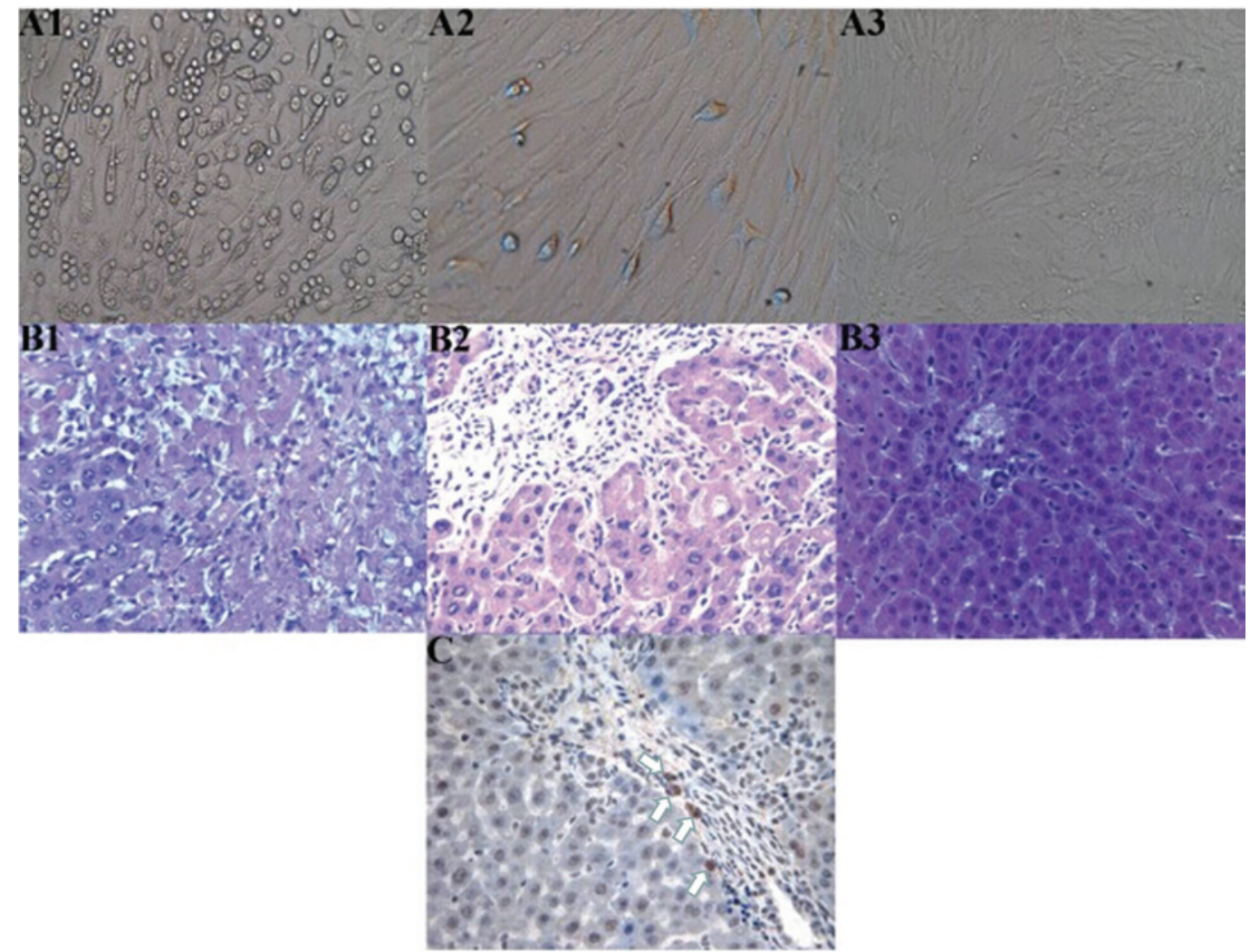

Figure 1. (A) Cell culture, (B) hepatic histopathological changes and (C) immunohistochemistry showing the location of the mesenchymal stem cells (MSCs). (A) Morphological changes of the MSCs; (A1) Primary culture for three days (magnification, x100) revealed a number of oval-shaped adherent cells and the partial stretching and deformation of cells, presenting as a polygon or clostridium; (A2) First generational passage cell culture (magnification, x200) showed a small number of confluent cells; (A3) Third generational passage cell culture for seven days (magnification, x50) exhibited whirlpool and pectiniform shapes. (B) Hepatic histopathological changes in each group on day 7 after orthotopic liver transplantation (OLT; hematoxylin and eosin stain; magnification, x200); (B1) Group A exhibited evident necrosis of hepatic cells; (B2) Group B exhibited evident inflammatory infiltration, predominantly concentrating in the portal area, without cellular necrosis; (B3) Group C manifested almost no evident inflammatory infiltration. (C) Location of MSCs in the grafts of patients in group $\mathrm{C}$ on day 7 following OLT was determined using SRY in situ hybridization (magnification, $\mathrm{x} 400$ ). A number of positive cells (white arrows) can be observed, with the cytoplasm and nucleus stained brown.

lethargic and were not eating. The rats responded slowly to an outside stimulus. After five to seven days, the rats began to show progressive jaundice, loss of awareness, apparent appetite reduction and gradual weight loss. The rats continued to appear lethargic and have a poor response to outside stimuli. Consequently, the rats succumbed naturally between days 9 and 13 after surgery. In the autopsy examination, no intra-abdominal ascites or distortion of the biliary stent casing were observed, while the edema of the liver and spleen was serious. In groups B and C, within seven days of the OLT, the recipients exhibited a passive mood, their diet was poor and their response to outside stimuli appeared a little clumsy.
However, in groups B and C recovery was observed $\sim 14$ days after the OLT, with the rats becoming active, improving their diet and gradually increasing in weight at one month after surgery. After five weeks the recipients in group B began to die, due to chronic immune rejection.

Hepatic functional measurements. On day 7 after the OLT, hepatic function in group $\mathrm{C}$ was significantly improved compared with groups A and B (Table I).

Histopathological examination. On day 7 after the OLT, group A rats exhibited strong acute rejection, and substan- 
Table II. Comparison of graft pathological classification among the three groups on day 7 following OLT.

\begin{tabular}{lcccc}
\hline Groups & Class zero & Class one & Class two & Class three \\
\hline Group A & 0 & 0 & 0 & 6 \\
Group B & 0 & 3 & 3 & 0 \\
Group C & 3 & 3 & 0 & 0 \\
\hline
\end{tabular}

Classification according to the standard recommended by Williams et al (17). OLT, orthotopic liver transplantation.

Table III. Expression of TGF- $\beta_{1}$, IL-10 and IL-12 in the three groups after OLT.

\begin{tabular}{|c|c|c|c|c|c|c|c|c|c|c|c|c|c|}
\hline \multirow[t]{2}{*}{ Groups } & \multirow[t]{2}{*}{$\mathrm{n}$} & \multicolumn{4}{|c|}{ TGF- $\beta_{1}$} & \multicolumn{4}{|c|}{ IL-10 } & \multicolumn{4}{|c|}{$\mathrm{IL}-12$} \\
\hline & & - & + & ++ & +++ & - & + & ++ & +++ & - & + & ++ & +++ \\
\hline A & 6 & 2 & 4 & 0 & 0 & 2 & 4 & 0 & 0 & 0 & 1 & 5 & 0 \\
\hline B & 6 & $0^{\mathrm{a}}$ & 2 & 4 & 0 & 0 & 0 & 1 & 5 & 1 & 5 & 0 & 0 \\
\hline $\mathrm{C}$ & 6 & 0 & 0 & 1 & 5 & $0^{\mathrm{b}}$ & 0 & 0 & 6 & 6 & 0 & 0 & 0 \\
\hline $\mathrm{H}$ & & \multicolumn{4}{|c|}{13.859} & \multicolumn{4}{|c|}{15.065} & \multicolumn{4}{|c|}{14.606} \\
\hline $\mathrm{P}$ & & \multicolumn{4}{|c|}{0.001} & \multicolumn{4}{|c|}{0.001} & \multicolumn{4}{|c|}{0.001} \\
\hline
\end{tabular}

${ }^{\mathrm{a} T G F}-\beta_{1}$, Group B compared with A, U=4.000, P=0.014; ' $\mathrm{b} \mathrm{L}-10$, Group C compared with B, U=15.000, P=0.317; $\alpha$ '=0.05/3. Expression was determined to be negative $(-)$, weak positive $(+)$, medium positive $(++)$ or strong positive $(+++)$. TGF, transforming growth factor; IL, interleukin; OLT, orthotopic liver transplantation.

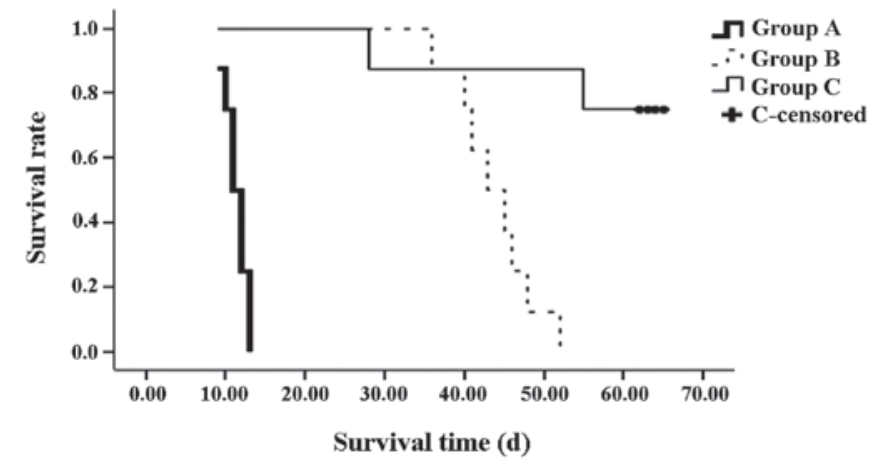

Figure 2. Survival curve of the recipients in each group following orthotopic liver transplantation. Survival times in groups B and C were significantly longer compared with group $\mathrm{A}(\mathrm{P}<0.01)$. The survival rate of group $\mathrm{C}$ was also higher compared with group $\mathrm{B}(\mathrm{P}<0.01)$.

tial necrosis of the hepatic cells was observed. Group B rats presented with mild acute rejection and there was evident inflammatory infiltration, mainly concentrating in the portal area, without cellular necrosis. Group $\mathrm{C}$ rats manifested the mildest rejection and there was almost no observations of inflammatory infiltration, with the structures clearly visible. In the three groups, pathological changes caused by acute immune rejection were classified according to the standard recommended by Williams et al (17) (Table II and Fig. 1-B).

Immunohistochemical results. TGF- $\beta_{1}$ was mainly secreted by MSCs and their differentiated cells, including T helper 1 (Th1) cells. IL-10 was primarily secreted by T helper 2 cells, mono- nuclear cells, MSCs and their differentiated cells. IL-12 was predominantly secreted by antigen-presenting-cells (APCs), such as dendritic cells, and mononuclear cells and Th1 cells. The majority of these cells were found in the portal area. When the nucleus and part of the cytoplasm were stained with brown particles, the cells were regarded to exhibit positive expression. A total of five high-density positive cell areas in the portal area were randomly selected under a microscope (magnification, $\mathrm{x} 400)$ to observe the proportion of positive cells. If the percentage of positive cells was $<10 \%, 10-25 \%, 26-50 \%$ and $>50 \%$, the cells were regarded as negative (-), weak positive (+), medium positive $(++)$ and strong positive $(+++)$, respectively. Weak positive and medium positive samples were considered to exhibit low expression, while strong positive samples were considered to have high expression (18) (Table III).

SRY in situ hybridization. On day 7 after the OLT, the results revealed a number of positive cells, with part of the cytoplasm and the nucleus stained brown. These cells were the MSCs obtained from the male donor rats containing the $\mathrm{Y}$ chromosome, and were primarily found in the portal area (Fig. 1-C).

Survival analysis. From the Kaplan-Meier survival curve, the survival times in groups B (median, 44 days) and $\mathrm{C}$ (median, 63 days) were shown to be significantly longer compared with the rats in group A (median, 11 days; both $\mathrm{P}<0.01)$. In addition, the survival rate of the rats in group $\mathrm{C}$ was significantly higher compared with group $\mathrm{B}(\mathrm{P}<0.01)$. On day 28 after the OLT, one rat from group $\mathrm{C}$ succumbed 
to biliary tract obstruction. An additional rat succumbed on day 55; however, the cause was unknown (Fig. 2).

\section{Discussion}

MSCs are characterized by their ability to self-renew and differentiate into various cell lineages. The cells have a wide range of sources. Research into the clinical application of MSCs is increasing, with in vitro and in vivo studies (19-21) demonstrating the immunoregulatory effect of MSCs. Bartholomew et al (22) found that MSCs were able to prolong allogeneic skin graft survival in baboons, despite the cells being collected from a 'third party' (not from the donors or recipients). In addition, MSC infusion suppressed immune rejection, while the recipients did not inflict an immune rejection against the MSCs. Schatton et al (23) also reported that MSCs had the same effect in a model of allogeneic heart transplantation.

Clinical liver transplantation has become an effective treatment for advanced chronic liver disease and certain cases of acute liver failure. Postoperative acute immune rejection seriously affects the outcome of liver transplantation. In clinical practice, a number of novel immunosuppressants are used to maintain liver function by controlling immune rejection following liver transplantation. However, administration of these drugs is limited due to the high-cost, severe toxicity and side effects. In addition, these drugs are unable to prevent chronic immune rejection. The ideal pathway of immunosuppressants for prolonging graft survival is to induce specific immune tolerance of recipients-to-grafts $(24,25)$. Previous studies $(26,27)$ have indicated that the third generational passage cells of MSCs had a strong proliferation capability and vital force, with the cell survival rate reaching $>90 \%$. In the present study, these conditions were also demonstrated by elaborative observation under an inverted microscope during the whole process of MSC culture (Fig. 1A). Therefore, the third generational passage cells of donor MSCs were synchronously infused into recipients during the OLT. Compared with the other groups, synchronously infused MSCs combined with postoperative immunosuppressant therapy were shown to reduce the dose of postoperative immunosuppressant application, relieve acute immune rejection and induce immune tolerance, through measuring hepatic function, observing hepatic pathological changes, detecting immune cytokines and observing the survival times of the recipients. These effects may be due to a number of reasons. Firstly, MSCs may immunoregulate the functions of host $\mathrm{T}$ cells (28-30) by direct regulation (31,32), where the MSCs change the immune function through direct contact between cells to regulate the ratio changes of $\mathrm{T}$ cell subsets, or indirect regulation (33-35), where MSCs may inhibit the growth and activation of $\mathrm{T}$ cells to cause relative changes to the $T$ cell subsets in order to induce a lower $\mathrm{T}$ cell response, through the secretion of immune cytokines, including TGF- $\beta_{1}$, hepatocyte growth factor, and metabolic products, such as prostaglandin E2 or indole-2,3-dioxygenase. Beyth et al (9) indicated that MSCs affected the maturation of normal APCs indirectly to cause T cells to become unresponsive, through the secretion of IL-10 and the inhibition of monocyte IL-12 secretion, ultimately inhibiting immune rejection. In the current study, strong positive expression of the immune cytokines, TGF- $\beta_{1}$ and IL-10, was observed in group $\mathrm{C}$, and expression was more evident compared with group B. Expression in group A was weak positive. In addition, the expression of IL-12 in groups A, B and C was observed to be medium positive, weak positive and negative, respectively. MSCs are known to increase the secretion of TGF- $\beta_{1}$ and IL-10 (36) and inhibit the secretion of IL-12 following OLT, which is in accordance with the aforementioned conclusions (37). An additional possible mechanism by which MSCs may exert their effects is that MSCs may inhibit the formation of cytotoxic lymphocytes and reduce the activation of NK cells (38). Finally, MSCs may depress the differentiation and maturation of dendritic cells and interfere with the function of endocytosis; MSCs may also upregulate $\mathrm{CD} 8{ }^{+} \mathrm{CD} 28 \mathrm{~T}$ cells to inhibit immune rejection (39). FK506 is an immunosuppressant and MSCs have an inhibitory immune rejection effect. Consequently, in the present study, the survival times of the recipients in group $\mathrm{C}$ were significantly longer compared with group $\mathrm{A}(\mathrm{P}<0.01)$ and group $\mathrm{B}(\mathrm{P}<0.01)$, with a median survival time of $>63$ days. On day 7 after the OLT, the levels of AST, ALT and TBIL in group C were significantly lower compared with group A $(\mathrm{P}<0.01)$ and group $\mathrm{B}$ $(\mathrm{P}<0.01$; Table I). With regard to histopathological examination, group A exhibited severe immune rejection, while the reaction in group $\mathrm{C}$ appeared significantly milder when compared with groups A and B. Thus, synchronous infusion of MSCs in a rat model of OLT was shown to reduce the dose of postoperative immunosuppressants applied, improving the long-term immune tolerance.

MSCs are hypothesized to inhibit immune rejection primarily through direct contact between cells and soluble immune cytokines by paracrine regulation. The pathway is very significant in alleviating transplant immune rejection (40-43). Thereby, it was necessary to determine the homing ability of MSCs to the graft liver in group C. Currently, there are a variety of methods to determine the homing ability. In the present study, Y chromosome location was selected (donors and recipients were female, while donors for MSC extraction were male). MSCs have a powerful homing ability and the liver is the main homing organ for transplantation cells, with $29-45 \%$ of transplantation cells locating in the liver $(20,21)$. In the present study, MSCs were infused $\left(1 \times 10^{6} / 200 \mathrm{~g}\right)$ into the recipients via the portal vein immediately after anastomosing the bile duct. Through SRY in situ hybridization, positive cells with areas of the cytoplasm and nucleus stained brown were observed on day 7 after the OLT, primarily on the portal area (Fig. 1C). These results suggested that, to a certain degree, the homing ability and immunosuppressive effects of MSCs were associated with MSC application.

In conclusion, MSCs may contribute to reducing the postoperative immunosuppressant dose by inhibiting immune rejection and inducing immune tolerance. In addition, MSCs have a wide range of sources and are easily isolated in culture; thus, MSC therapy has good potential for reducing the severe toxicity and side effects of immunosuppressant drugs, suppressing immune rejection and inducing immune tolerance following clinical liver transplantations in the near future. However, the detailed mechanisms require further research.

\section{Acknowledgements}

The study was supported by grants from the National Natural Science Foundation of China (no. 30760239) and the 
Science \& Technology Innovation Fund of Xinjiang Medical University (no. XJC201267).

\section{References}

1. Starzl TE, Marchioro TL, Faris TD, Carey TA and Otte JB: The therapeutic potential of whole organ transplantation. J Am Med Womens Assoc 21: 207-209, 1966.

2. Bozbas SS, Eyuboglu FO, Ozturk Ergur F, Gullu Arslan N, Sevmis $\mathrm{S}$, Karakayali H, et al: Pulmonary complications and mortality after liver transplant. Exp Clin Transplant 6: 264-270, 2008.

3. Tanaka T, Takatsuki M, Soyama A, Torashima Y, Kinoshita A, Yamaguchi I, et al: Evaluation of immune function under conversion from Prograf to Advagraf in living donor liver transplantation. Ann Transplant 18: 293-298, 2013.

4. Bogdanos DP, Gao B and Gershwin ME: Liver immunology. Compr Physiol 3: 567-598, 2013

5. Gerlach UA, Vogt K, Schlickeiser S, Meisel C, Streitz M, Kunkel D, et al: Elevation of $\mathrm{CD}^{+}$differentiated memory T cells is associated with acute cellular and antibody-mediated rejection after liver transplantation. Transplantation 95: 1512-1520, 2013.

6. Di Nicola M, Carlo-Stella C, Magni M, Milanesi M, Longoni PD, Matteucci P, et al: Human bone marrow stromal cells suppress T-lymphocyte proliferation induced by cellular or nonspecific mitogeni stimuli Blood 99: 3838-3843, 2002.

7. Rasmusson I, Ringdén O, Sundberg B and Le Blanc K: Mesenchymal stem cells inhibit the formation of cytotoxic T lymphocytes, but not activated cytotoxic T lymphocytes or natural killer cells. Transplantation 76: 1208-1213, 2003.

8. Le Blanc K, Rasmusson I, Götherström C, Seidel C, Sundberg B, Sundin M, et al: Mesenchymal stem cells inhibit the expression of CD25 (interleukin-2 receptor) and CD38 on phytohaemagglutinin-activated lymphocytes. Scand J Immunol 60: 307-315, 2004.

9. Beyth S, Borovsky Z, Mevorach D, Liebergall M, Gazit Z, Aslan $\mathrm{H}$, et al: Human mesenchymal stem cells alter antigen-presenting cell maturation and induce T-cell unresponsiveness. Blood 105: 2214-2219, 2005

10. Wood KJ, Bushell A and Hester J: Regulatory immune cells in transplantation. Nat Rev Immunol 12: 417-430, 2012.

11. English K, Ryan JM, Tobin L, Murphy MJ, Barry FP and Mahon BP. Cell contact, prostaglandin E(2) and transforming growth factor beta 1 play non-redundant roles in human mesenchymal stem cell induction of CD4+CD25(High) forkhead box P3+ regulatory T cells. Clin Exp Immunol 156: 149-160, 2009.

12. Kordelas L, Rebmann V, Ludwig AK, Radtke S, Ruesing J, Doeppner TR, et al: MSC-derived exosomes: a novel tool to treat therapy-refractory graft-versus-host disease. Leukemia 28: 970-973, 2014.

13. Pittenger MF, Mackay AM, Beck SC, Jaiswal RK, Douglas R, Mosca JD, et al: Multilineage potential of adult human mesenchymal stem cells. Science 284: 143-147, 1999.

14. Minguell JJ, Erices A and Conget P: Mesenchymal stem cells. Exp Biol Med (Maywood) 226: 507-520, 2001.

15. Kamada N and Calne RY: A surgical experience with five hundred thirty liver transplants in the rat. Surgery 93: 64-69, 1983.

16. Wei F, Wang TZ, Zhang J, Yuan ZY, Tian HY, Ni YJ, et al: Mesenchymal stem cells neither fully acquire the electrophysiological properties of mature cardiomyocytes nor promote ventricular arrhythmias in infarcted rats. Basic Res Cardiol 107: 274, 2012.

17. Williams JW, Peters TG, Vera SR, Britt LG, van Voorst SJ and Haggitt RC: Biopsy-directed immunosuppression following hepatic transplantation in man. Transplantation 39: 589-596, 1985.

18. Kojc N, Zidar N, Vodopivec B and Gale N: Expression of CD34 alpha-smooth muscle actin, and transforming growth factor betal in squamous intraepithelial lesions and squamous cell carcinoma of the larynx and hypopharynx. Hum Pathol 36: 16-21, 2005.

19. Yi T and Song SU: Immunomodulatory properties of mesenchymal stem cells and their therapeutic applications. Arch Pharm Res 35: 213-221, 2012.

20. Kim YH, Wee YM, Choi MY, Lim DG, Kim SC and Han DJ: Interleukin (IL)-10 induced by $\mathrm{CD} 1 \mathrm{lb}(+)$ cells and IL-10-activated regulatory $\mathrm{T}$ cells play a role in immune modulation of mesenchymal stem cells in rat islet allografts. Mol Med 17: 697-708, 2011.

21. Hong ZF, Huang XJ and Yin ZY: Immunocharacteristics of bone marrow mesenchymal stem cell. Zhonghua Gan Zang Bing Za Zhi 17: 53-58, 2009 (In Chinese).
22. Bartholomew A, Sturgeon C, Siatskas M, Ferrer K, McIntosh K, Patil S, et al: Mesenchymal stem cells suppress lymphocyte proliferation in vitro and prolong skin graft survival in vivo. Exp Hematol 30: 42-48, 2002

23. Schatton T, Yang J, Chandraker A, Sayegh MH and Frank MH: In vivo immunomodulatory function of $\mathrm{ABCB}^{+}$dermal mesenchymal stem cells. Transplantation 82: 185-186, 2006.

24. Pan MX, Hou WL, Zhang QJ, Gong DH, Cheng Y, Jian GD and Gao Y: Infusion of autologous mesenchymal stem cells prolongs the survival of dogs receiving living donor liver transplantation. Nan Fang Yi Ke Da Xue Xue Bao 29: 1783-1786, 2009 (In Chinese).

25. Zhang LS, Liu QF, Huang K, Zhang Y, Fan ZP and Huang SL: Mesenchymal stem cells for treatment of steroid-resistant chronic graft-versus-host disease. Zhonghua Nei Ke Za Zhi 48: 542-546, 2009 (In Chinese).

26. Colter DC, Class R, DiGirolamo CM and Prockop DJ: Rapid expansion of recycling stem cells in cultures of plastic-adherent cells from human bone marrow. Proc Natl Acad Sci USA 97: 3213-3218, 2000.

27. Jiang Y, Jahagirda BN, Reinhardt RL, Schwartz RE, Keene CD, Ortiz-Gonzalez XR, et al: Pluripotency of mesenchymal stem cells derived from adult marrow. Nature 418: 41-49, 2002.

28. Ye Z, Wang Y, Xie HY and Zheng SS: Immunosuppressive effects of rat mesenchymal stem cells: involvement of $\mathrm{CD} 4{ }^{+} \mathrm{CD} 25^{+}$regulatory T cells. Hepatobiliary Pancreat Dis Int 7: 608-614, 2008

29. Sekiya I, Larson BL, Smith JR, Pochampally R, Cui JG and Prockop DJ: Expansion of human adult stem cells from bone marrow stroma: conditions that maximize the yields of early progenitors and evaluate their quality. Stem Cells 20: 530-541, 2002.

30. Xia X, Chen W, Ma T, Xu G, Liu H, Liang C, et al: Mesenchymal stem cells administered after liver transplantation prevent acute graft-versus-host disease in rats. Liver Transpl 18: 696-706, 2012.

31. Krampera M, Glennie S, Dyson J, ScottD, LaylorR, Simpson E, et al: Bone marrow mesenchymal stem cells inhibit the response of naive and memory antigen-specific $\mathrm{T}$ cells to their cognate peptide. Blood 101: 3722-3729, 2003

32. Popp FC, Renner P, Eggenhofer E, Slowik P, Geissler EK, Piso P, et al: Mesenchymal stem cells as immunomodulators after liver transplantation. Liver Transpl 15: 1192-1198, 2009.

33. Di Nicola M, Carlo-Stella C, Magni M, Milanesi M, Longoni PD, Matteucci $\mathrm{P}$, et al: Human bone marrow stromal cells suppress T-lymphocyte proliferation induced by cellular or nonspecific mitogenic stimuli. Blood 99: 3838-3843, 2002.

34. Tobin LM, Healy ME, English K and Mahon BP: Human mesenchymal stem cells suppress donor CD4(+) T cell proliferation and reduce pathology in a humanized mouse model of acute graft-versus-host disease. Clin Exp Immunol 172: 333-348 2013.

35. Meisel R, Zibert A, Laryea M, Göbel U, Däubener W and Dilloo D: Human bone marrow stromal cells inhibit allogeneic T-cell responses by indoleamine 2,3-dioxygenase-mediated tryptophan degradation. Blood 103: 4619-4621, 2004.

36. Niu J, Yue W, Song Y, Zhang Y, Qi X, Wang Z, et al: Prevention of acute liver allograft rejection by IL-10-engineered mesenchymal stem cells. Clin Exp Immunol 176: 473-484, 2014.

37. Han J, Zhao J, Xu J and Wen Y: Mesenchymal stem cells genetically modified by lentivirus-mediated interleukin-12 inhibit malignant ascites in mice. Exp Ther Med 8: 1330-1334, 2014.

38. Aggarwal S and Pittenger MF: Human mesenchymal stem cells modulate allogeneic immune cell responses. Blood 105: 1815-1822, 2005.

39. Jiang XX, Zhang Y, Liu B, Zhang SX, Wu Y, Yu XD and Mao N Human mesenchymal stem cells inhibit differentiation and function of monocyte-derived dendritic cells. Blood 105: 4120-4126, 2005.

40. Pan GZ, Yang Y, Zhang J, Liu W, Wang GY, Zhang YC, et al: Bone marrow mesenchymal stem cells ameliorate hepatic ischemia/reperfusion injuries via inactivation of the MEK/ERK signaling pathway in rats. J Surg Res 178: 935-948, 2012

41. Kuroda Y, Kitada M, Wakao S and Dezawa M: Bone marrow mesenchymal cells: how do they contribute to tissue repair and are they really stem cells? Arch Immunol Ther Exp (Warsz) 59: 369-378, 2011

42. Pournasr B, Mohamadnejad M, Bagheri M, Aghdami N, Shahsavani M, Malekzadeh $\mathrm{R}$ and Baharvand $\mathrm{H}$ : In vitro differentiation of human bone marrow mesenchymal stem cells into hepatocyte-like cells. Arch Iran Med 14: 244-249, 2011.

43. Secchiero P, Corallini F, Zavan B, Tripodo C, Vindigni V and Zauli G: Mesenchymal stem cells display hepato-protective activity in lymphoma bearing xenografts. Invest New Drugs 30: 803-807, 2012. 